\title{
Meningkatkan kemandirian belajar peserta didik dengan menggunakan M-Learning berbasis android di SMK Muhammadiyah 5 Kepanjen Malang (Learning media used for online learning during the Covid-19 pandemic)
}

\author{
Nanik Khurotul Aini, Heny Kusdiyanti *, Madziatul Churiyah \\ Universitas Negeri Malang, Jl. Semarang No. 5 Malang, Jawa Timur, Indonesia \\ *Penulis korespondensi, Surel: heny.kusdiyanti.fe@um.ac.id
}

Paper received: 2-1-2021; revised: 23-1-2021; accepted: 30-1-2021

\begin{abstract}
Abstrak
Dalam masa pandemi covid-19 seperti saat ini dibutuhkan media yang membuat peserta didik tidak bosan pada saat melaksanakan pembelajaran daring. Media M-Learning berbasis android dapat dijadikan sebagai alternatif pada proses kegiatan belajar mengajar secara daring di masa pandemi seperti saat ini. Media pembelajaran M-Learning juga dapat digunakan untuk menunjang pada saat kegiatan pembelajaran di kelas karena dapat diakses melalui smartphone peserta didik masingmasing. Oleh karena itu, penelitian ini bertujuan untuk menghasilkan media M-Learning berbasis android pada materi Menerapkan prosedur pencatatan surat/dokumen masuk dan keluar kelas X. Produk media pembelajaran yang dikembangkan dilengkapi dengan beberapa menu dan gambar serta video yang dapat membantu peserta didik dalam meningkatkan kemandirian belajar. Penelitian dan pengembangan ini menggunakan model Research and Development (R\&D) Borg and Gall yang telah dimodifikasi. Teknik analisis data yang digunakan adalah teknis analisis data kuantitatif dan kualitatif. Hasil penelitian dan pengembangan ini adalah M-Learning berbasis android pada mata pelajaran Administrasi Umum yang diberi nama Caraku yang telah dinyatakan sangat valid dan layak digunakan dalam pembelajaran Administrasi Umum oleh ahli media, ahli materi, dan 6 peserta didik uji coba kelompok kecil serta terbukti terdapat perbedaan kemandirian belajar secara signiflkan pada uji coba kelompok besar dimana hasil rata-rata data kemandirian belajar kelas eksperimen lebih tinggi dari pada kelas kontrol. Sehingga dapat disimpulkan bahwa CARAKU layak dan efektif digunakan sebagai media pembelajaran untuk meningkatkan kemandirian belajar peserta didik pada mata pelajaran Administrasi Umum di kelas X.
\end{abstract}

Kata kunci: penelitian dan pengembangan; media pembelajaran; mobile learning; android; kemandirian belajar

\section{Pendahuluan}

Pandemi covid-19 yang terjadi saat ini memberikan dampak yang cukup signifikan pada berbagai aspek kehidupan salah satu yang terpengaruh adalah sektor pendidikan. Selama masa pandemi covid-19 pembelajaran dirumah atau online menjadi solusi melanjutkan sisa semester dengan memanfaatkan berbagai fasilitas penunjang yang mendukung (Herliandry dkk, 2020). Teknologi berperan besar dalam pembelajaran terutama di situasi pandemi covid19 seperti saat ini, teknologi memberikan kemudahan kepada pendidik serta peserta didik dalam melakukan pembelajaran jarak jauh atau biasa disebut PJJ (Salsabila dkk, 2020). Salah satu jenis PJJ adalah pembelajaran daring. Sistem pembelajaran daring merupakan sistem pembelajaran tanpa tatap muka secara langsung antar guru dan peserta didik, melainkan secara online yang menggunakan jaringan internet. Guru dan peserta didik melakukan pembelajaran bersama dan dalam waktu yang sama dengan menggunakan aplikasi (Asmuni, 2020). Oleh karena itu dibutuhkan suatu media pembelajaran agar pada saat pembelajaran di kelas lebih bervariasi dan tidak membosankan. 
Media pembelajaran merupakan alat bantu yang digunakan oleh guru dalam proses kegiatan kegiatan pembelajaran (Alhafidz and Haryono, 2018). Media pembelajaran yang kini mulai beragam mengikuti perkembangan ilmu pengetahuan dan teknologi yakni media pembelajaran yang berbasis elektronik dapat dijadikan sebagai alternatif pembelajaran pada saat melaksanakan pembelajaran secara daring salah satunya yaitu mobile learning (MLearning). Penggunaan media pembelajaran M-Learning berbasis android diharapkan memudahkan peserta didik dalam memahami materi pelajaran yang dikemas menggunakan media smartphone. Penggabungan antara materi dengan penggunaan media teknologi dapat memungkinkan pembelajaran menjadi lebih luas dan cepat (Bernacki et al., 2020).

Media pembelajaran M-Learning yang dikembangkan dalam penelitian ini yaitu MLearning berbasis android. Media ini disajikan dalam bentuk aplikasi mobile yang bisa diinstal di smartphone android peserta didik masing-masing. Media juga didesain dengan menarik yang dilengkapi dengan gambar, materi, video pembelajaran serta soal evaluasi yang hasilnya dapat diketahui langsung oleh peserta didik dan secara otomatis terkirim melalui email yang sudah terintegrasi dengan media sehingga guru dapat mengetahui pemahaman peserta didik melalui soal evaluasi yang telah dikerjakan. Beberapa penelitian sebelumnya yang juga membahas tema ini adalah penelitian yang dilakukan oleh (Sari et al., 2020; Huda et al., 2019; Rahmat et al., 2019; Crompton and Burke, 2018; Amirullah and Hardinata, 2017; Astuti et al., 2017; Rahmawati and Mukminan, 2017; Al-Emran et al., 2016; Wahyuni and Djukri, 2016) berdasarkan beberapa penelitian tersebut dapat disimpulkan bahwa media pembelajaran MLearning berbasis android dapat meningkatkan kemandirian belajar peserta didik.

Akan tetapi berdasarkan hasil observasi dan wawancara dengan guru mata pelajaran Administrasi Umum kelas X OTKP diperoleh informasi bahwa selama masa pandemi covid-19 ini kegiatan belajar mengajar dilaksanakan secara daring melalui Google Classroom. peserta didik tidak yakin dengan kemampuannya sendiri, dalam mempelajari materi peserta didik masih harus menunggu instruksi dari guru, bahkan ada yang meminta arahan dari temannya di kelas, peserta didik sering menyontek jawaban dari tugas temannya, pada saat guru memberikan pertanyaan peserta didik kurang percaya diri dalam menyampaikan pendapatnya. Kemudian saat melaksanakan pembelajaran daring beberapa peserta didik tidak mengumpulkan tugas yang diberikan guru dengan tepat waktu. Hal tersebut menunjukan bahwa kemandirian belajar peserta didik masih tergolong rendah, padahal di SMK Muhammadiyah 5 Kepanjen sudah menerapkan Kurikulum 2013 revisi yang mengharuskan peserta didik untuk lebih aktif dan memiliki sikap kemandirian dalam belajar.

Berdasarkan permasalahan tersebut peneliti mencoba mengembangkan media MLearning berbasis android yang dapat digunakan pada mata pelajaran Administrasi Umum. Media didesain menarik agar peserta didik tidak bosan pada saat mengikuti pembelajaran daring. Pengembangan media M-Learning berbasis android dapat dijadikan sebagai alternatif pada proses kegiatan belajar mengajar secara daring di masa pandemi seperti saat ini. Karena media yang bersifat fleksibel dapat digunakan kapanpun dan dimanapun. Dalam media MLearning berbasis android ini akan dilengkapi dengan beberapa fitur menarik seperti kuis, gambar, dan video. Media pembelajaran M-Learning juga dapat digunakan untuk menunjang pada saat kegiatan pembelajaran di kelas karena dapat diakses melalui smartphone peserta didik masing-masing. 


\section{Metode}

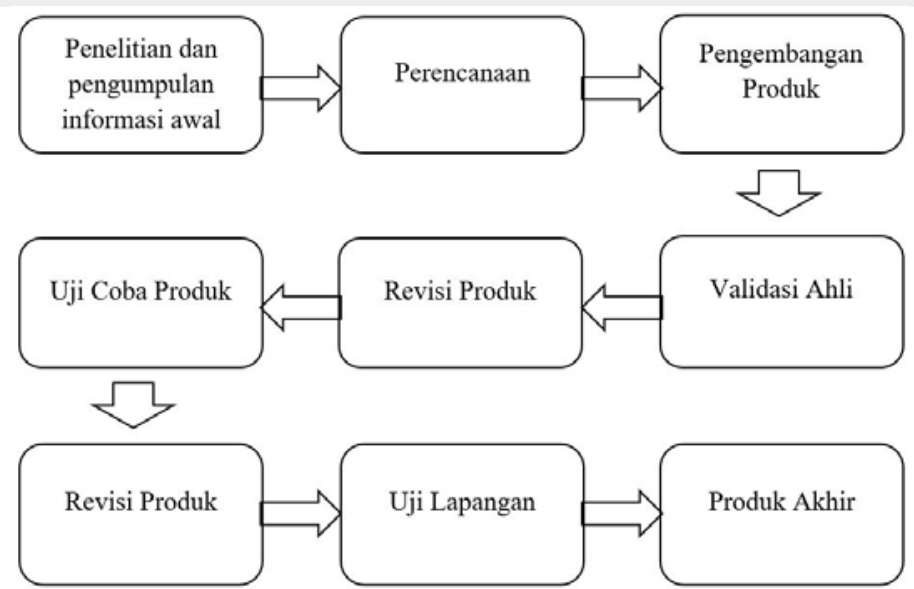

Gambar 1. Langkah-Langkah Penelitian

Penelitian ini menggunakan model Research and Development Borg and Gall yang dimodifikasi menjadi sembilan langkah karena keterbatasan waktu dan tenaga dalam pembuatan produk (Rahmat et al., 2019). Adapun tujuan dari penelitian ini yaitu untuk menghasilkan produk media pembelajaran M-Learning berbasis android, mengetahui tingkat kelayakan media pembelajaran M-Learning berbasis android serta mengetahui apakah media pembelajaran M-Learning yang dikembangkan dapat meningkatkan kemandirian belajar peserta didik.

Langkah pertama, peneliti melakukan penelitian dan pengumpulan informasi awal terkait dengan permasalahan yang ada di sekolah dan juga kegiatan pembelajaran pada mata pelajaran Administrasi Umum di kelas X. Langkah kedua, peneliti melakukan perencanaan terkait media yang akan dikembangkan. Langkah ketiga, peneliti melakukan pengembangan produk awal media pembelajaran yang akan dikembangkan dan dapat menjadi solusi atas permasalahan yang ditemukan pada langkah pengumpulan informasi awal serta mulai membuat media pembelajaran sesuai rancangan yang telah ditentukan pada langkah sebelumnya. Langkah keempat, media yang dihasilkan peneliti diuji kelayakannya oleh validator ahli yakni satu orang ahli materi dan satu orang ahli media. Langkah kelima, produk media yang telah diuji kelayakannya kemudian direvisi berdasarkan saran dan pendapat dari validator ahli. Langkah keenam, uji coba produk yang dilakukan kepada kelompok kecil yang berjumlah 6 orang yakni kelas eksperimen (OTKP-2). Langkah ketujuh yakni revisi produk media pembelajaran berdasarkan masukan, saran dan pendapat dari kelompok kecil. Langkah kedelapan, peneliti melakukan uji coba lapangan kepada kelas eksperimen yakni OTKP-2 untuk menilai apakah produk media yang dikembangkan dapat meningkatkan kemandirian belajar. langkah kesembilan yakni produk media pembelajaran M-Learning yang sudah siap untuk digunakan diberikan kepada peserta didik agar dapat digunakan di smartphone masingmasing.

Data yang dihasilkan pada penelitian ini meliputi data kuantitatif dan data kualitatif, dimana data kuantitatif merupakan data yang diperoleh berdasarkan data hasil validasi ahli materi, data hasil validasi ahli media, data hasil uji coba kelompok kecil, dan data kemandirian belajar peserta didik. Sedangkan data kualitatif diperoleh berdasarkan penarikan kesimpulan 
berdasarkan pendapat, saran dan kritik dari ahli media, ahli materi dan pengguna sebagai subjek uji coba lapangan yang digunakan untuk perbaikan media M-learning. Data kualitatif, data kuantitatif, dan kemandirian belajar dianalisis dengan cara mencari rata-rata persentase.

\section{Hasil dan Pembahasan}

Produk yang dihasilkan dalam penelitian dan pengembangan ini adalah M-Learning berbasis android pada mata pelajaran Administrasi Umum. Produk media pembelajaran MLearning ini diberi nama CARAKU yang merupakan singkatan dari Kompetensi Dasar yang digunakan dalam penelitian ini yakni Menerapkan prosedur pencatatan surat/dokumen masuk dan keluar. Adapun menu dalam media ini akan dijelaskan melalui Gambar 2 di bawah ini.

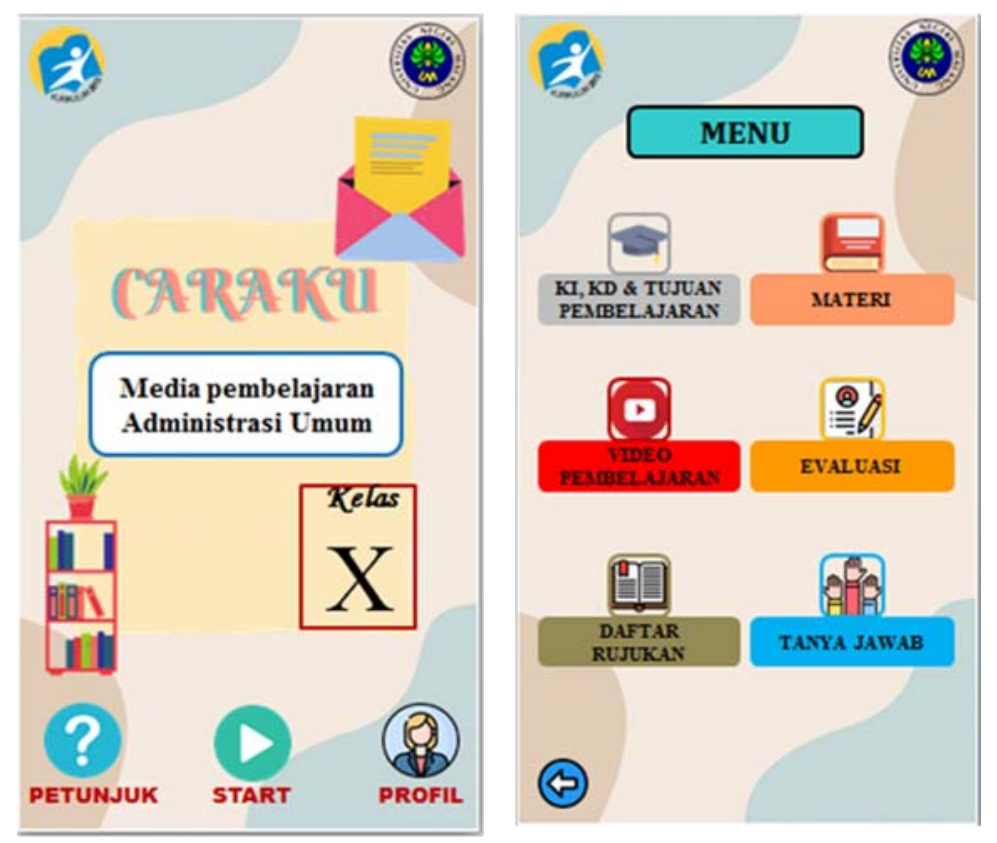

Gambar 2. Tampilan Halaman Awal M-Learning

Setelah membuka aplikasi media M-Learning akan muncul "Halaman Awal”, pengguna dapat menuju Halaman KI/KD dan Petunjuk seperti pada Gambar 3. 


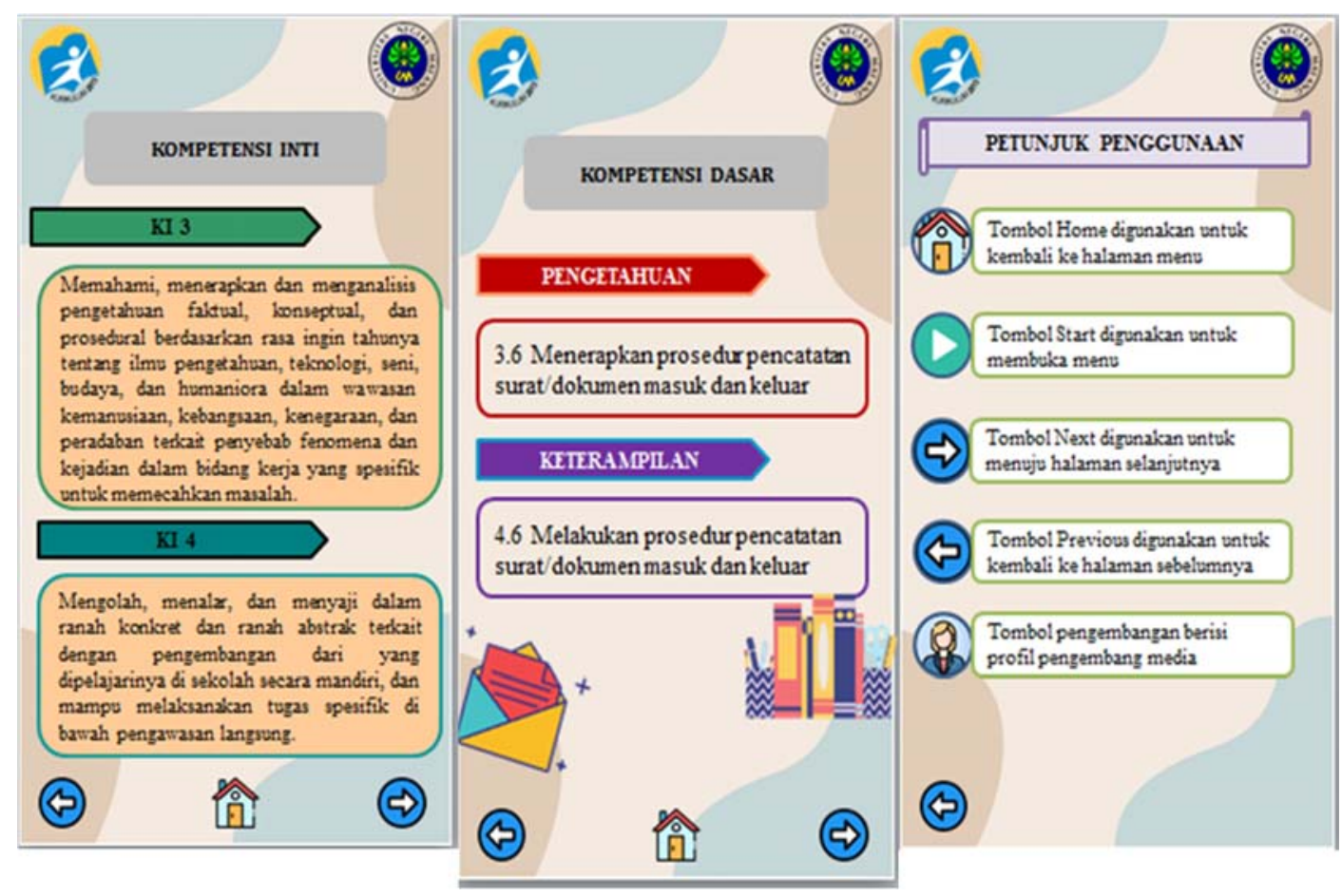

Gambar 3. Halaman KI/KD dan Petunjuk aplikasi M-Learning

Hasil validasi dan uji coba media pembelajaran M-Learning CARAKU oleh ahli materi, ahli media, dan uji coba kelompok kecil secara keseluruhan disajikan dalam Tabel 1.

Tabel 1.

\begin{tabular}{llll}
\hline No & Validasi & Presentase & Kriteria \\
\hline 1 & Ahli Materi & $98,18 \%$ & Sangat Valid \\
2 & Ahli Media & $97,39 \%$ & Sangat Valid \\
3 & Uji Coba Kelompok Kecil & $90 \%$ & Dapat Digunakan \\
Rata-Rata & $95,19 \%$ & Sangat Valid \\
\hline
\end{tabular}

Berdasarkan Tabel 1, diketahui rata-rata persentase validasi dan uji coba keseluruhan sebesar 95,19\%, sehingga dapat disimpulkan bahwa media pembelajaran M-Learning yang dikembangkan peneliti yakni CARAKU dinyatakan 'Sangat Valid' dan layak digunakan dalam pembelajaran Administrasi Umum di kelas X SMK Muhammadiyah 5 Kepanjen. Hal ini sesuai dengan penelitian sebelumnya, dimana hasil validasi ahli materi, ahli media dan uji coba kelompok kecil dijadikan dasar penentuan apakah media pembelajaran yang dikembangkan layak atau tidak digunakan dalam pembelajaran (Anam, 2017), (Wahyuni and Djukri, 2016), (Lubis and Ikhsan, 2015). Hasil analisis data kemandirian belajar peserta didik ini disajikan pada Tabel 2. 
Tabel 2

\begin{tabular}{|c|c|c|c|c|c|c|c|}
\hline \multirow[t]{2}{*}{ Aspek } & \multicolumn{5}{|c|}{ Rata-Rata Aspek Nilai Kemandirian Belajar Peserta Didik } & \multirow{2}{*}{$\begin{array}{l}\text { Rata- } \\
\text { Rata } \\
\text { Total } \\
\text { Skor }\end{array}$} & \multirow[t]{2}{*}{ Keterangan } \\
\hline & $\begin{array}{l}\text { Kepercayaan } \\
\text { Diri }\end{array}$ & $\begin{array}{l}\text { Tanggung } \\
\text { Jawab }\end{array}$ & $\begin{array}{l}\text { Inisiatif } \\
\text { Sendiri }\end{array}$ & Disiplin & $\begin{array}{l}\text { Sumber } \\
\text { Belajar }\end{array}$ & & \\
\hline $\begin{array}{l}\text { Kelas } \\
\text { Kontrol }\end{array}$ & $59,23 \%$ & $58,84 \%$ & $60,76 \%$ & $60,51 \%$ & $60 \%$ & $59,86 \%$ & $\begin{array}{l}\text { Kemandirian } \\
\text { belajar } \\
\text { peserta } \\
\text { didik rendah }\end{array}$ \\
\hline $\begin{array}{l}\text { Kelas } \\
\text { Eksperimen }\end{array}$ & $76,53 \%$ & $84,9 \%$ & $76,13 \%$ & $77,06 \%$ & $87,2 \%$ & $80,36 \%$ & $\begin{array}{l}\text { Kemandirian } \\
\text { belajar } \\
\text { peserta } \\
\text { didik tiggi }\end{array}$ \\
\hline
\end{tabular}

Berdasarkan Tabel 2 dapat dilihat bahwa terdapat perbedaan nilai kemandirian belajar peserta didik kelas kontrol dan kelas eksperimen. Pada kelas kontrol yaitu X OTKP 1 diperoleh rata-rata nilai kemandirian peserta didik sebesar 59,86\% yang dapat dikategorikan kemandirian belajar peserta didik rendah sedangkan untuk kelas kelas eksperimen yaitu X OTKP 2 diperoleh rata-rata nilai kemandirian belajar peserta didik sebesar 80,36\% yang dapat dikategorikan kemandirian belajar peserta didik tinggi. Dengan hasil tersebut dapat disimpulkan bahwa media pembelajaran M-Learning CARAKU dapat meningkatkan kemandirian belajar peserta didik pada mata pelajaran Administrasi Umum karena nilai ratarata yang diperoleh kelas eksperimen lebih tinggi dibandingkan nilai rata-rata yang diperoleh kelas kontrol.

\section{Simpulan}

Penelitian dan pengembangan ini menghasilkan produk media pembelajaran MLearning berbasis android pada mata pelajaran Administrasi Umum untuk meningkatkan kemandirian belajar peserta didik. Media pembelajaran ini diberi nama CARAKU yang dapat diinstall pada smartphone peserta didik masing-masing. Media pembelajaran pada penelitian ini telah dinyatakan 'Sangat Valid' dan layak digunakan dalam pembelajaran Administrasi Umum melalui validasi oleh ahli materi, ahli media dan uji coba kelompok kecil. Selain itu, media pembelajaran CARAKU ini terbukti efektif dapat meningkatkan kemandirian belajar peserta didik dimana terdapat perbedaan yang signifikan antara tingkat kemandirian belajar peserta didik yang menggunakan media CARAKU dibandingkan dengan peserta didik yang tidak menggunakan media CARAKU. Media pembelajaran M-Learning CARAKU ini hanya berfokus pada beberapa Kompetensi Dasar dan terbatas pada sistem operasi android sehingga diharapkan kedepannya peneliti selanjutnya dapat mengembangkan media pembelajaran pada sistem operasi lainnya seperti iOS..

\section{Ucapan Terima Kasih}

Penulis mengucapkan terimakasih kepada Universitas Negeri Malang dan SMK Muhammadiyah 5 Kepanjen yang telah memfasilitasi dan memberi izin kepada peneliti untuk melakukan kegiatan penelitian dan pengembangan ini. 


\section{Daftar Rujukan}

Al-Emran, M., Elsherif, H. M., \& Shaalan, K. (2016). Investigating attitudes towards the use of mobile learning in higher education. Computers in Human behavior, 56, 93-102. https://doi.org/10.1016/j.chb.2015.11.033

Alhafidz, M. R. L., \& Haryono, A. (2018). Pengembangan mobile learning berbasis android sebagai media pembelajaran ekonomi. Jurnal Pendidikan Ekonomi, 11(2), 118-124.

Amirullah, G., \& Hardinata, R. (2017). Pengembangan mobile learning bagi pembelajaran. JKKP (Jurnal Kesejahteraan Keluarga Dan Pendidikan), 4(02), 97-101. https://doi.org/10.21009/JKKP.042.07

Anam, C., (2017). Pengembangan Mobile Learning Berbasis Android Sebagai Media Pembelajaran Pada Materi Akuntansi Kas. J. Pendidik. Akunt. JPAK 5.

Asmuni, A. (2020). Problematika Pembelajaran Daring di Masa Pandemi Covid-19 dan Solusi Pemecahannya. Jurnal Paedagogy, 7(4), 281-288. https://doi.org/10.33394/jp.v7i4.2941

Astuti, I. A. D., Sumarni, R. A., \& Saraswati, D. L. (2017). Pengembangan media pembelajaran fisika mobile learning berbasis android. Jurnal Penelitian \& Pengembangan Pendidikan Fisika, 3(1), 57-62.

Bernacki, M. L., Greene, J. A., \& Crompton, H. (2020). Mobile technology, learning, and achievement: Advances in understanding and measuring the role of mobile technology in education. Contemporary Educational Psychology, 60, 101827. https://doi.org/10.1016/j.cedpsych.2019.101827

Crompton, H., \& Burke, D. (2018). The use of mobile learning in higher education: A systematic review. Computers \& Education, 123, 53-64. https://doi.org/10.1016/j.compedu.2018.04.007

Herliandry, L. D. Nurhasanah., Suban, ME, \& Heru, K. 2020. Pandemic Learning during the Covid-19. Jurnal Teknologi Pendidikan, 22(1), 65-70. https://doi.org/10.21009/jtp.v22i1.15286

Huda, M. N., Mulyono, M., Rosyida, I., \& Wardono, W. (2019, February). Kemandirian Belajar Berbantuan Mobile Learning. In PRISMA, Prosiding Seminar Nasional Matematika (Vol. 2, pp. 798-806).

Lubis, I.R., Ikhsan, J., (2015). Pengembangan Media Pembelajaran Kimia Berbasis Android Untuk Meningkatkan Motivasi Belajar Dan Prestasi Kognitif Peserta Didik SMA. J. Inov. Pendidik. IPA 1, 191-201. https://doi.org/10.21831/jipi.v1i2.7504

Rahmat, R.F., Mursyida, L., Rizal, F., Krismadinata, K., Yunus, Y., (2019). Pengembangan media pembelajaran berbasis mobile learning pada mata pelajaran simulasi digital. J. Inov. Teknol. Pendidik. 6, 116-126. https://doi.org/10.21831/jitp.v6i2.27414

Rahmawati, E.M., Mukminan, M., (2017). Pengembangang m-learning untuk mendukung kemandirian dan hasil belajar mata pelajaran Geografi. J. Inov. Teknol. Pendidik. 4, 157-166. https://doi.org/10.21831/jitp.v4i2.12726

Salsabila, U.H., Sari, L.I., Lathif, K.H., Lestari, A.P., Ayuning, A., (2020). Peran Teknologi Dalam Pembelajaran Di Masa Pandemi Covid-19. Al-Mutharahah J. Penelit. Dan Kaji. Sos. Keagamaan 17, 188-198. https://doi.org/10.46781/al-mutharahah.v17i2.138

Sari, N.I., Sulur, S., Pramono, N.A., (2020). Pengembangan M-Learning Physics for Fun Berbasis Android pada Materi Listrik Statis untuk Siswa SMA/MA. J. Ris. Pendidik. Fis. 4, 13-17. https://doi.org/10.17977/um058v4i1p13-17

Wahyuni, S., Djukri, D., (2016). Pengembangan Media Pembelajaran Berbantuan Komputer Dan Keefektifannya Terhadap Kemandirian Belajar Dan Penguasaan Konsep Bryophyte. J. Inov. Teknol. Pendidik. 3, 79-91. https://doi.org/10.21831/tp.v3i1.8262 